\title{
Incidence and underreporting of osseous wrist and hand injuries on whole-body computed tomographies at a level 1 trauma center
}

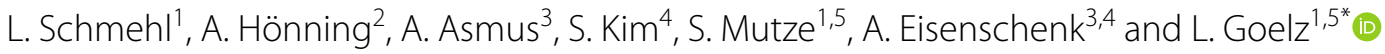

\begin{abstract}
Background: To investigate the incidence of osseous wrist and hand injuries on whole-body computed tomographies (WBCT) at an urban maximum-care trauma center, to report the number of missed cases in primary radiology reports, and to develop an algorithm for improved detection of these injuries.
\end{abstract}

Methods: Retrospective analysis reviewing all WBCT for a period of 8 months for osseous wrist and hand injuries. (1) Reconstruction of hands/wrists in three planes (thickness $1-2 \mathrm{~mm}$ ) and analysis by a blinded musculoskeletal radiologist. (2) Scanning of primary radiology reports and comparison to the re-evaluation. (3) Calculation of the diagnostic accuracy of WBCT during primary reporting. (4) Search for factors potentially influencing the incidence (trauma mechanism, associated injuries, Glasgow Coma Scale, artifacts). (5) Development of an algorithm to improve the detection rate.

Results: Five hundred six WBCT were included between 01/2020 and 08/2020. 59 (11.7\%) WBCT showed 92 osseous wrist or hand injuries. Distal intra-articular radius fractures occurred most frequently $(n=24,26.1 \%) ; 22$ patients (37.3\%) showed multiple injuries. The sensitivity of WBCT in the detection of wrist and hand fractures during primary evaluation was low with 4 positive cases identified correctly $(6.8 \% ; 95 \% \mathrm{Cl} 1.9$ to 16.5$)$, while the specificity was $100 \%$ ( $95 \%$ Cl 99.2 to 100.0). Forty-three cases (72.9\%) were detected on additional imaging after clinical reassessment. Twelve injuries remained undetected (20.3\%). Motorcycle accidents were more common in positive cases (22.0\% vs. $10.1 \%, p=0.006$ ). $98 \%$ of positive cases showed additional fractures of the upper and/or lower extremities, whereas $37 \%$ of the patients without osseous wrist and hand injuries suffered such fractures $(p<0.001)$. The remaining investigated factors did not seem to influence the occurrence.

Conclusion: Osseous wrist and hand injuries are present in 11.7\% on WBCT after polytrauma. $93.2 \%$ of injuries were missed primarily, resulting in a very low sensitivity of WBCT during primary reporting. Motorcycle accidents might predispose for these injuries, and they often cause additional fractures of the extremities. Clinical re-evaluation of patients and secondary re-evaluation of WBCT with preparation of dedicated multiplanar reformations are essential in polytrauma cases to detect osseous injuries of wrist and hand reliably.

*Correspondence: Leonie.Goelz@ukb.de

${ }^{1}$ Department of Radiology and Neuroradiology, BG Klinikum

Unfallkrankenhaus Berlin, Warener Str. 7, 12683 Berlin, Germany

Full list of author information is available at the end of the article permits use, sharing, adaptation, distribution and reproduction in any medium or format, as long as you give appropriate credit to the original author(s) and the source, provide a link to the Creative Commons licence, and indicate if changes were made. The images or other third party material in this article are included in the article's Creative Commons licence, unless indicated otherwise in a credit line to the material. If material is not included in the article's Creative Commons licence and your intended use is not permitted by statutory regulation or exceeds the permitted use, you will need to obtain permission directly from the copyright holder. To view a copy of this licence, visit http://creativecommons.org/licenses/by/4.0/. The Creative Commons Public Domain Dedication waiver (http://creativeco mmons.org/publicdomain/zero/1.0/) applies to the data made available in this article, unless otherwise stated in a credit line to the data. 
Trial registration: The study was registered prospectively on November 17th, 2020, at the German register for clinical trials (DRKS-ID: DRKS00023589).

Keywords: Osseous injuries, Wrist, Hand, Missed injuries, Underreporting, Whole-body computed tomographies, WBCT, Polytrauma

\section{Background}

Extremity injuries are frequently missed on wholebody computed tomographies (WBCT) depending on the patients'ability to express pain and the severity of additional injuries. Hence, overlooking of injuries is more likely to occur in cases of old, critically injured, and unconscious patients $[1,2]$. The quality of clinical exams and imaging, the experience of physicians, and their interdisciplinary cooperation also influence detection rates of injuries [3]. In an effort to reduce the number of missed injuries, the concept of repeated examinations was introduced: within a defined time-window after an accident, after stabilization of a patient, or after the patient regains consciousness, another thorough clinical exam is conducted, and existing diagnostic imaging is reviewed or complemented [4]. Injuries are then detected with a delay, but fractures of the extremities can usually be treated in a timely fashion [5].

Difficulties during interpretation of WBCT can occur because of artifacts which increase due to unfavorable bedding of patients for WBCT acquisition [6, 7]. Fractures of the carpus are detected on dedicated thin-slice CT of less than $1 \mathrm{~mm}$ thickness more accurately [8]. Additionally, reconstruction of each hand and wrist in coronal and sagittal planes after WBCT is intricate which makes thorough examination of these body parts very time-consuming after polytrauma.

Existing literature describes $14-60 \%$ extremity fractures among all missed injuries [3, 4, 9]. In a metaanalysis from $2008,4-33 \%$ of extremity fractures were located at the hand or wrist after polytrauma [10]. Recent studies on the prevalence of osseous wrist and hand fractures in polytraumatized patients at specialized centers are often based on patient records or trauma registries [11, 12]. However, imaging studies with modern computed tomography (CT) scanners could possibly visualize more subtle injuries and allow for introduction of a reference test through review by experienced musculoskeletal radiologists. Münn et al. reported $15.5 \%$ hand and forearm fractures upon retrospective review of ventilated trauma patients on WBCT [13]. We examined factors influencing the visibility of these injuries on WBCT in this cohort previously [14]. Yet, osseous injuries of the wrist and hand are relevant for all polytrauma patients, especially if long-term damages can be prevented and the working ability can be restored $[15,16]$.

In 2011 twenty different medical societies first co-published the German S3 guideline for the treatment of polytrauma and the severely injured and defined indications for WBCT after trauma [17]. This current study aims to assess the prevalence, injury patterns, trauma mechanisms, and potentially influencing factors of osseous wrist and hand fractures in a real-life polytrauma patient cohort examined with $\mathrm{WBCT}$ at a level 1 trauma center.

\section{Methods \\ Study design}

This retrospective analysis was registered prospectively at the German register for clinical trials (DRKSID: DRKS00023589) on November 17th, 2020 and conducted in accordance with the Declaration of Helsinki 2013. The institutional review board (Medical Association of Berlin, Germany, Eth-45/20) approved the study protocol and waived the necessity for written consent. The study consisted of seven phases: screening/enrollment, primary radiology report classification, reconstruction of hands/wrists, review by a blinded musculoskeletal radiologist, comparison of the primary report and re-evaluation, search for factors potentially influencing the incidence in imaging and patient records, and calculation of the diagnostic accuracy of WBCT during primary reporting. Figure 1 summarizes the study protocol according to the Strengthening the Reporting of Observational Studies in Epidemiology (STROBE) Initiative [18].

\section{Screening and enrollment}

Screening of consecutive WBCT was conducted from January 2020 to August 2020. Patients were treated due to suspected polytrauma according to the German S3 guideline for the treatment of polytrauma and the severely injured [17]. WBCT was indicated in cases with pathological vital signs, at least two relevantly injured body regions, and/or after relevant trauma mechanisms such as severe road traffic accidents and falls from heights of more than $3 \mathrm{~m}$ [20]. Eligible patients had to be $\geq 18$ years of age. Examinations due to a non-emergent cause and studies with incomplete depiction of hands or wrists were excluded from this study. 


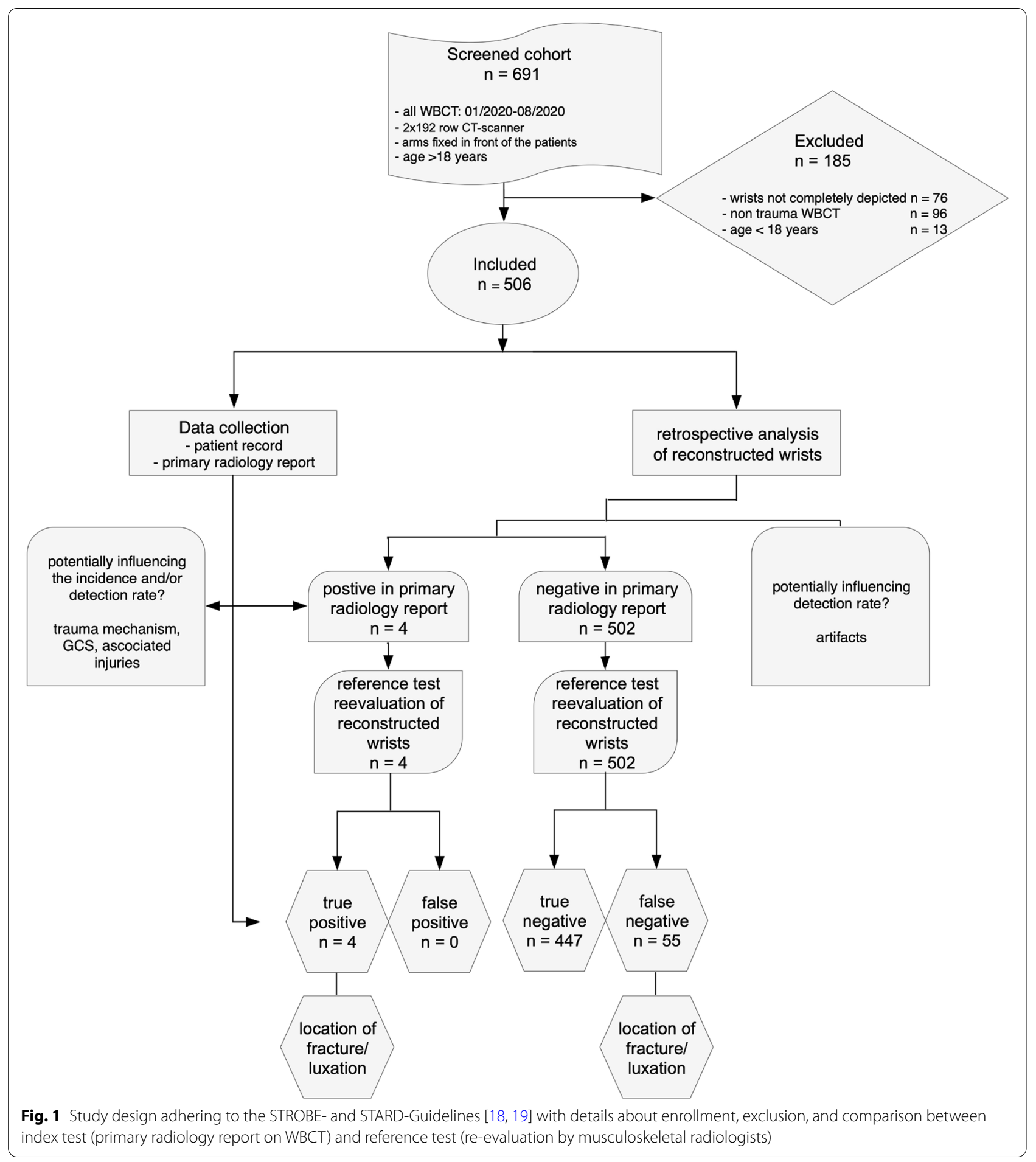

\section{Imaging}

WBCT were acquired using a double-source CT scanner with two 192 row detectors (Somatom Force, Siemens, Germany). Scans had a slice thickness of
$0.75 \mathrm{~mm}$ and were performed in spiral technique. The patients'arms were fixed in front of the patients during imaging. 


\section{Report classification and preparation of cases}

Fractures and luxations between the forearm (distal radius and ulnar) and the metacarpal bones were considered positive cases. After inclusion, primary radiology reports (RR) were reviewed manually and classified as either "positive-by-report" or "negative-by-report" by an independent reader. The types and locations of osseous wrist and hand injuries were recorded in a pseudonymized table per patient and side (Excel, Microsoft 365, USA). Coronal and sagittal reconstructions of $1-2 \mathrm{~mm}$ thickness were prepared with a post-processing software (IntelliSpace Portal 11, Philips, Netherlands) and stored in a Picture Archiving and Communication System (PACS) (IntelliSpace, Philips, Netherlands) separately for each wrist/hand.

\section{Reference test and discrepancy review}

Reconstructed images were reviewed by two musculoskeletal radiologists blinded to the primary radiology reports. Osseous injuries were recorded for each wrist/ hand. Uncertain cases were discussed to determine a conclusive result. Results of the reference test were classified as "positive-by-reference" or "negative-by-reference". The presence of beam-hardening, motion, or metal artifacts, and artifacts induced by contrast-agent in the veins of the upper extremities were recorded by the reviewers.

Comparison of primary $R R$ and reference test resulted in true positive, false positive, true negative, and false negative cases. False negative cases were further examined by an independent reader for secondary imaging (plain radiographs, CT, or MRI) and delayed diagnosis.

\section{Patient records}

For final data collection, records of included patients were reviewed for age, sex, trauma mechanism, vigilance upon primary presentation, and during hospitalization on the intensive care unit (ICU) using the Glasgow Coma Scale (GCS), additional injuries of the body, as well as the therapy of hand/wrist injuries. Cases of patients with missed hand/wrist injuries which had been discharged without correct diagnosis and therapy were examined by a board-certified hand surgeon for therapeutic consequences. Based on this review, the medical need for contacting these patients was determined.

\section{Endpoint analysis and statistical analysis}

Our reporting adhered to the Standards for Reporting of Diagnostic Accuracy (STARD) statement and recommendations [19]. Results of primary reporting on WBCT and secondary reporting on additional imaging compared with that of the reference standard (review by musculoskeletal radiologists) were reported as true positives (TP), false positives (FP), true negatives (TN), and false negatives (FN). The diagnostic accuracy was expressed as sensitivity, specificity, positive (PPV) and negative (NPV) predicted values with 95\% Clopper Pearson [21] confidence intervals $(\mathrm{CI})$.

Associations between the likelihood of suffering osseous wrist and hand injuries and various parameters (localization of osseous wrist/hand injuries, additional injuries, artifacts, trauma mechanism, and GCS) were evaluated via Pearson's chi squared two-sided test. $P$-values $<0.05$ were considered statistically significant.

Descriptive statistics included arithmetic mean, standard deviation (SD), minimum and maximum (range), and absolute (n) and relative (\%) proportions. Missing values were not imputed but presented for each variable if existing. The SPSS software package for Windows, version 28 (IBM, Armonk, NY, USA) was employed for all statistical analyses.

\section{Results}

Six hundred ninety-one WBCT were screened according to the inclusion and exclusion criteria between January 2020 and August 2020 at the study center (Fig. 1). Seventy-six cases were excluded because of incomplete depiction of wrists, 96 WBCT were performed for nontraumatic causes, and 13 minors were excluded from the study.

Five hundred six consecutive WBCT of 137 (27.1\%) female and $369(72.9 \%)$ male patients were included with a mean age of 53 (18-98) years. Basic demographics were similar in patients with and without osseous injuries of wrist and hand (Table 1).

\section{Primary analysis}

The radiology reports of WBCT identified $n=4$ osseous injuries of the wrist and hand. These cases were confirmed during review by the reference as true positive, none of them were false positive cases. Among the remaining 502 cases, the musculoskeletal radiologists identified $n=55$ additional false negative cases either with fractures $(n=42)$, luxations $(n=2)$, or both fractures and luxations $(n=11)$. Four hundred forty-seven cases were true negative. After review by the gold standard the prevalence of osseous hand and wrist fractures was $11.7 \%(n=59) .55(93.2 \%)$ of these injuries were missed during primary reporting. Table 2 summarizes the identified cases of fractures and luxations during primary reporting and re-evaluation.

The diagnostic accuracy of primary reporting after WBCT for diagnosing osseous wrist and hand injuries was low with a sensitivity of only $6.8 \%$ (95\% CI 1.9-16.5\%) and a specificity of $100.0 \%$ (95\% CI $99.2-100.0 \%$ ) (Table 3). 
Table 1 Characteristics of polytraumatized patients

\begin{tabular}{|c|c|c|c|}
\hline Variable & No wrist/hand injuries & Wrist/hand Injuries & Total \\
\hline $\mathrm{n}$ & 447 & 59 & 506 \\
\hline Mean age, years (SD [range]) & 53.4 (19.7 [18 to 98]) & $49.9(17.2$ [18 to 88$])$ & $53.0(19.5$ [18 to 98$])$ \\
\hline \multicolumn{4}{|l|}{ Gender, n (\%) } \\
\hline Male & $324(72.5)$ & $45(76.3)$ & $369(72.9)$ \\
\hline Female & $123(27.5)$ & $14(23.7)$ & $137(27.1)$ \\
\hline \multicolumn{4}{|l|}{ ICU, n (\%) } \\
\hline Yes & $147(32.9)$ & $22(37.3)$ & $169(33.4)$ \\
\hline No & $300(67.1)$ & $37(62.7)$ & $337(66.6)$ \\
\hline GCS at ER (SD [range]) & $12.9(4.3[3$ to 15$])$ & $13.9(2.9[3$ to 15$])$ & $13.0(4.2[3$ to 15$])$ \\
\hline GCS at ICU (SD [range]) & $9.7(5.9[3$ to 15$])$ & $11.6(5.4[3$ to 15$])$ & $9.9(5.9[3$ to 15$])$ \\
\hline \multicolumn{4}{|l|}{ Motorcycle accident, $\mathrm{n}(\%)^{*}$} \\
\hline Yes & $45(10.1)$ & $13(22.0)$ & $58(11.5)$ \\
\hline No & $398(89.0)$ & $45(76.3)$ & $443(87.5)$ \\
\hline Missing & $4(0.9)$ & $1(1.7)$ & $5(1.0)$ \\
\hline \multicolumn{4}{|c|}{ Additional extremity injury, n (\%) } \\
\hline Yes & $165(36.9)$ & $58(98.3)$ & $223(44.1)$ \\
\hline No & $281(62.9)$ & $1(1.7)$ & $282(55.8)$ \\
\hline Missing & $1(0.2)$ & 0 & $1(0.1)$ \\
\hline
\end{tabular}

SD Standard Deviation, ICU Intensive Care Unit, GCS Glasgow Coma Scale, ER Emergency Room, ${ }^{*} p=0.006,{ }^{*} p<0.001$.

Table 2 Cross tabulations of findings during primary reporting versus reference test

\begin{tabular}{|c|c|c|c|c|c|c|}
\hline & & \multicolumn{4}{|l|}{ Re-evaluation } & \multirow[t]{2}{*}{ Total } \\
\hline & & No wrist/hand injury & Fracture & Luxation & Both & \\
\hline \multirow{3}{*}{$\begin{array}{l}\text { Primary Report- } \\
\text { ing on WBCT }\end{array}$} & Wrist/hand injury & 0 & $4(8.7 \%)$ & 0 & 0 & $4(0.8 \%)$ \\
\hline & No wrist/hand injury & 447 (100\%) & $42(91.3 \%)$ & $2(100 \%)$ & $11(100 \%)$ & $502(99.2 \%)$ \\
\hline & Total & 447 & 46 & 2 & 11 & 506 \\
\hline \multirow{3}{*}{$\begin{array}{l}\text { Secondary Imag- } \\
\text { ing and Reporting }\end{array}$} & Wrist/hand injury & 0 & $34(73.9 \%)$ & $2(100 \%)$ & $11(100 \%)$ & 47 (9.3\%) \\
\hline & No wrist/hand injury & 447 (100\%) & $12(26.1 \%)$ & 0 & 0 & $459(90.7 \%)$ \\
\hline & Total & 447 & 46 & 2 & 11 & 506 \\
\hline
\end{tabular}

Table 3 Measures of diagnostic accuracy of primary reporting on WBCT and secondary reporting after additional imaging

\begin{tabular}{lllllllll}
\hline Index test & TP & FP & TN & FN & Sensitivity (95\% Cl) & Specificity (95\% Cl) & PPV (95\% Cl) & NPV (95\% Cl) \\
\hline Primary reporting on WBCT & 4 & 0 & 447 & 55 & $6.8 \%(1.9-16.5 \%)$ & $100.0 \%(99.2-100.0 \%)$ & $100.0 \%(39.8-100.0 \%)$ & $89.0 \%(86.0-91.6 \%)$ \\
Secondary imaging and reporting & 47 & 0 & 447 & 12 & $79.7 \%(67.2-89.0 \%)$ & $100.0 \%(99.2-100.0 \%)$ & $100.0 \%(92.5-100.0 \%)$ & $97.4 \%(95.5-98.6 \%)$
\end{tabular}

TP True positive, FP False positive, TN True negative, FN False negative, PPV Positive predicted value, NPV Negative predicted value, CI Confidence interval

After additional, secondary imaging 47 patients with osseous injuries of wrist or hand were identified. Most of these cases $(n=36)$ were identified through additional plain radiographs shortly after WBCT. Secondary imaging using CT $(n=6)$ and MRI $(n=1)$ was less common. $20.3 \%(n=12)$ of cases with injuries remained undetected until discharge. The overall diagnostic accuracy after WBCT and secondary imaging for diagnosing osseous wrist and hand injuries in the patient cohort after suspected polytrauma clearly increased when using an additional imaging modality with a sensitivity of $79.7 \%$ (95\% CI $67.2-89.0 \%$ ) and a specificity of $100.0 \%$ (95\% CI 99.2-100.0\%) (Table. 2). 


\section{Types of osseous injuries}

Ninety-two different osseous injuries were reported, 22 patients suffered multiple injuries. Distal intraarticular radius fractures occurred most frequently $(n=24,26.1 \%)$. Fractures of the ulna process $(n=18$, $19.6 \%)$, distal extra-articular radius fractures $(n=10$, $10.9 \%)$, distal ulna fractures $(n=6,6.5 \%)$, fractures of Os triquetrum $(n=5,5.4 \%)$ and Os pisiforme $(n=2$, $2.2 \%)$, scaphoid fractures $(n=4,4.3 \%)$, fractures of hamulus ossis hamati $(n=2,2.2 \%)$, and fractures of the various metacarpal bones $(n=19,20.7 \%)$ were the other types of fractures described in the collective. Two (2.6\%) luxations, one of the distal radio-ulnar joint and one of the radio-joint were observed.

\section{Association between various parameters and the likelihood of injuries Trauma mechanism}

In the group with osseous injuries, falls accounted for 22 (37.2\%), motor-bicycle accidents for 13 (22.0\%), car accidents for 10 (16.9\%), bicycle accidents for 7 (11.9\%), and accidents as pedestrians for $5(8.5 \%)$ of cases. Two accidents were not described in patient records. Motor-bicycle accidents were described significantly less frequent in patients without osseous injuries of wrist and hand ( $n=45,10.1 \% ; p=0.006$ ) (Table. 1, Fig. 2). Falls from heights $>3 \mathrm{~m}$ were the most common reason for WBCT in this group $(n=219,49.0 \%)$.

\section{Vigilance}

169 (33.4\%) patients were treated in the ICU. The fractions of patients treated in the ICU did not differ significantly between patients with and without hand/ wrist injuries (37.3\% vs. $32.9 \%, p=0.61)$. Mean GCS was similar in both patient groups at presentation in the emergency room (ER) and in the ICU. Vigilance was further analyzed for patients with osseous wrist/ hand injuries to evaluate the missed rate in a dichotomic fashion for patients with mild impairment but reliable expression, and localization of pain $(\mathrm{GCS} \geq 13$ points) and patients with more severe cognitive limitations (GCS 3-12 points). The fraction of missed cases did not differ significantly in patients with GCS 3-12 and patients with GCS $>12(28.6 \%$ vs. $19.2 \%, p=0.56)$.

\section{Injury patterns}

$58(98.3 \%)$ of patients with osseous injuries of wrist or hand suffered additional injuries of the upper and/or lower extremities while only 165 (36.9\%) of patients without wrist/hand injuries showed concomitant extremity fractures $(p<0.001)$, (Fig. 2). The pelvis was injured in 16 (27.1\%) patients with wrist/hand injuries compared to 55 patients $(12.3 \%)$ without wrist/hand injuries $(p=0.21)$. In patients with wrist/hand injuries the head $(n=33,55.9 \%)$, thorax $(n=18,30.5 \%)$, spine $(n=15,25.4 \%)$, and abdomen $(n=5,8.5 \%)$ were injured in descending frequency, whereas the head $(n=234,52.3 \%)$, thorax $(n=162,36.2 \%)$, spine $(n=148,33.1 \%)$, and abdomen $(n=42,9.4 \%)$ were injured in patients without wrist/hand injuries. More than one organ system was injured in $22(37.3 \%)$ cases with osseous hand and wrist injuries vs. 182 (40.7\%) cases without these osseous injuries.

\section{Artifacts}

Artifacts were reported in 114 (22.9\%) cases $(n=9 / 15.3 \%$ of cases with and 105/23.5\% of cases without osseous wrist or hand injuries). They were mostly caused by contrast agent in distal veins of the hands $(n=73,62.9 \%)$ and foreign bodies $(n=25,21.6 \%)$. Due to the low percentage of documented artifacts in patients with wrist and hand injuries, the influence of artifacts on primary detection rates on WBCT was not formally tested.

\section{Clinical relevance}

Twenty-three patients were treated surgically and 24 were treated nonoperatively. Twelve non-displaced fractures of wrist and hand but no luxations remained undetected until discharge: three patients with distal intra-articular radius fractures, three patients with fractures of the 5th metacarpal bone, three patients with fractures of the 2nd metacarpal bone, two patients with fractures of the Os triquetrum, and one patient with a fracture of the distal scaphoid tubercle. A board-certified hand surgeon reviewed the cases and determined that after a time-gap of at least 10 months, physical and radiological followup of these patients were no longer medically indicated in almost all cases. All injuries could have been treated nonoperatively with immobilization. Alternatively, the distal intra-articular radius fractures and the fractures

(See figure on next page.)

Fig. 2 A 52-year-old male patient suffered a motorcycle accident and was examined using WBCT according to the S3 guideline for the treatment of polytrauma and the severely injured [17]. Multiplanar reformations in sagittal planes show distal intraarticular fractures of the radius of both wrists (A right side, B left side). Imaging showed additional injuries of the left lower extremity with proximal fracture of the fibula on a coronal reformation (C), and fracture of the medial malleolus on coronal (D) and sagittal (E) reformations. Motorcycle accidents might predispose for injuries of wrist and hand, and they often cause additional fractures of the extremities 


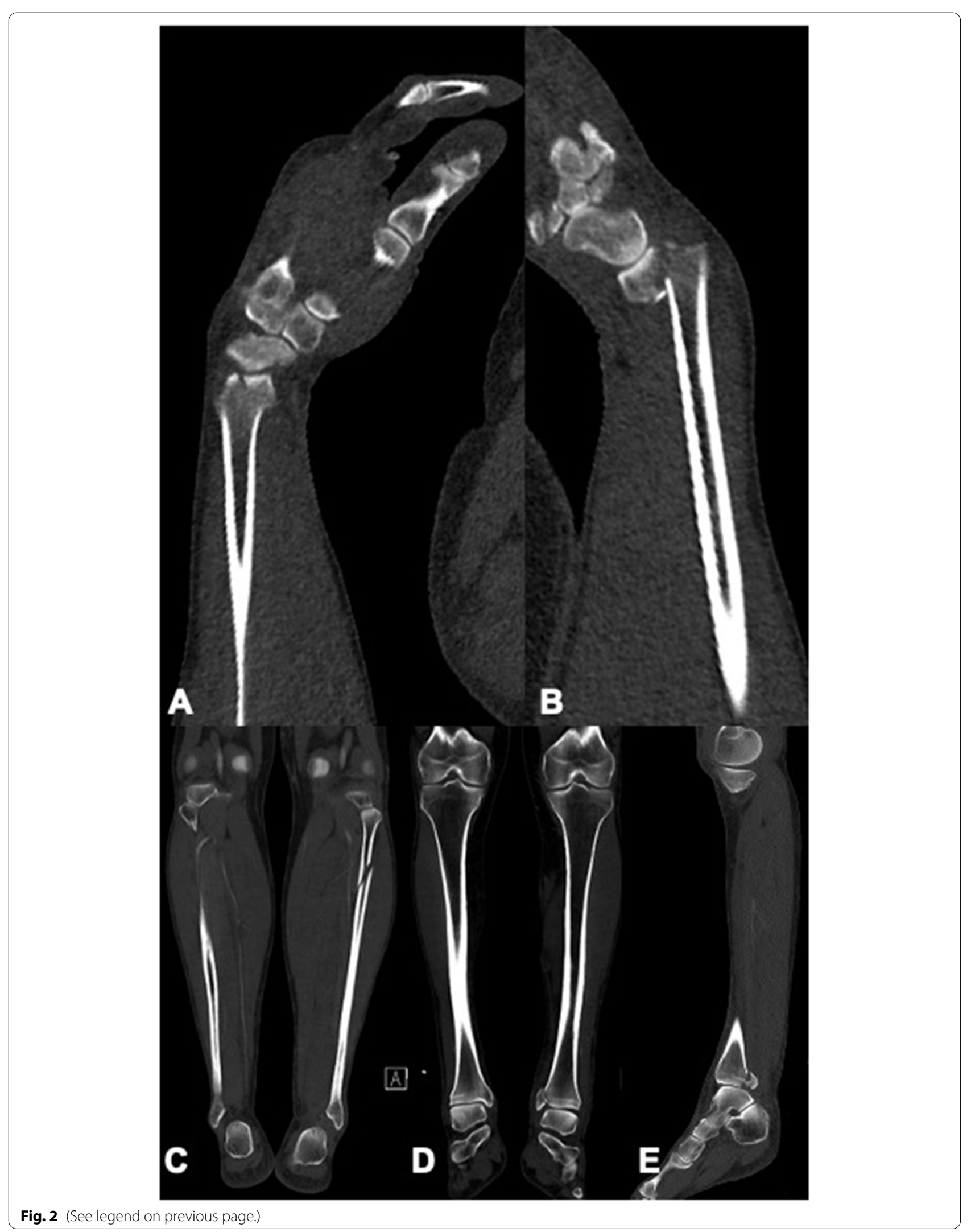


of metacarpal bones $(n=9)$ could have been treated surgically. Two patients, one with distal intra-articular radius fracture and one with a fracture of the 2nd metacarpal bone, died due to severe injuries. However, two young patients, one with distal intra-articular radius fracture and one with distal scaphoid tubercle fracture were informed and invited back for follow-up radiographs and examination motivated by the employer's liability insurance association. Both fractures were consolidated properly without signs of post-traumatic arthrosis.

\section{Discussion}

\section{Incidence}

The frequency of osseous injuries of the wrist and hand on WBCT was $11.7 \%$ in this cohort of patients after severe trauma. Distal intra-articular radius fractures occurred most frequently (26.1\%). In recent imaging and register studies incidences varied between 15.5\% for fractures of hand and forearm in ventilated patients and $36.1 \%$ for osseous and soft-tissue injuries [12, 13]. Ferree et al. reported an incidence of $3.5 \%$ for fractures and dislocations of the hand with a predisposition for fractures of the metacarpal bones (48\%) [11]. Our recent study included 32 fractures of the hand, most of these injuries (59.4\%) were also fractures of the metacarpal bones.

It appears reasonable, that the frequency of osseous hand and wrist injuries is influenced by the characteristics of the analyzed patient cohort and that the methods of a CT imaging study differ significantly from a retrospective review of patient records or a register study. One reason for a lower proportion of osseous hand and wrist injuries in the current patient collective might be differences in study design. The selection of the screening cohort was based on the German S3 guideline for the treatment of polytrauma and the severely injured [20] and consisted of a typical, reallife cohort of all trauma patients who were examined via WBCT during the study period. An alternate approach through patient records and data bases, including patients based on the severity of injuries, should increase the pretest probability of the examination results [12]. For the same reason, the incidence of osseous wrist and hand fractures might be higher in a cohort of ventilated patients, which have potentially suffered greater severity of injuries or high-impact trauma.

Additionally, our study and the publication by FritscheOestern et al. did not reveal a significant impact of a low GCS on osseous injuries of the hand or wrist [12]. Also, examination of injury patterns of patients with and without osseous injuries of wrist and hand did not support a mere association of the incidence of osseous wrist/hand injuries and the number and severity of other injuries. An accumulation of motorcyclists and patients with associated additional fractures of the extremities sets focus on the mechanics and force of an accident. Osseous injuries of the wrist and hand can follow selective mono-trauma through a fall from a standing height but can be more complex with multiple fractures in high-impact injuries [22, 23]. An understanding of specific trauma mechanisms and associated injuries can be beneficial in suspecting and diagnosing osseous injuries of the wrist and hand.

\section{Underreporting}

Underreporting occurred in $93.2 \%$ of osseous wrist and hand injuries, therefore diagnostic accuracy was low for WBCT during primary reporting. After repeated examination, secondary imaging, and reporting, $20.3 \%$ of the injuries remained unreported. In literature, the frequencies of missed wrist/hand fractures differ between 4.1 and $32.9 \%[10,12,14]$. Missed injuries have been shown to be more likely in intubated and severely injured patients $[24,25]$. Previous data also suggests that on-call duty predisposes for missed fractures and other injuries [14, 26]. Nevertheless, reasons for underreporting were not identified by this current study.

In addition, the subtlety of fractures plays an important role during the diagnostic process [27]. Pfeifer and Pape reviewed that $15-22.3 \%$ of all missed injuries were clinically relevant [10]. In the process of this current study, 2 of 12 patients with missed injuries were recalled for reexamination and follow-up imaging as suggested by the employer's liability insurance association. According to a board-specialized hand surgeon, surgical treatment of these 12 missed injuries was not mandatory. However, it cannot be excluded that failure to detect these injuries and to prescribe immobilization led to worsened clinical outcomes.

In an attempt to reduce the number of missed fractures, authors have suggested improvement of training of clinicians and radiologists, and some promoted the importance of radiographs in diagnosing extremity fractures [27-29]. However, the era of WBCT with the ability to examine patients from head to toe, and the basic radiological principle to apply as little radiation as reasonably achievable (ALARA $=$ as low as reasonably achievable), demands for critical discussion about the possibilities of WBCT and concurrent responsibilities of clinicians and radiologists [30]. The availability of high-quality imaging of wrists and hands on WBCT can be regarded as an opportunity to avoid additional radiation exposure through plain radiographs despite 
their low contribution to the overall radiation exposure of patients [31]. Admittedly, providing multiplanar reformations of each wrist and hand is a time-consuming process and in cases of polytraumatized patients not the primary concern of clinicians and radiologist. But the importance of multiplanar reformations should be undeniable considering the typical unordered position of hands on WBCT and studies about the additional use of multiplanar reformations i.e., for diagnosing scaphoid fractures [32].

\section{Algorithm to improve detection of osseous wrist and hand} injuries

The concept of re-examination and re-evaluation of existing imaging after polytrauma is routine procedure at the study site. In cases of suspected wrist and hand fractures however, clinical suspicion led to additional, mostly radiographic imaging, and increased detection of osseous wrist and hand injuries from 6.8 to $79.7 \%$.

In trauma surgery, the concept of tertiary survey is commonly established to ensure re-examination of patients after emergency care, typically within $24 \mathrm{~h}$ after admission, and again after patients reach consciousness

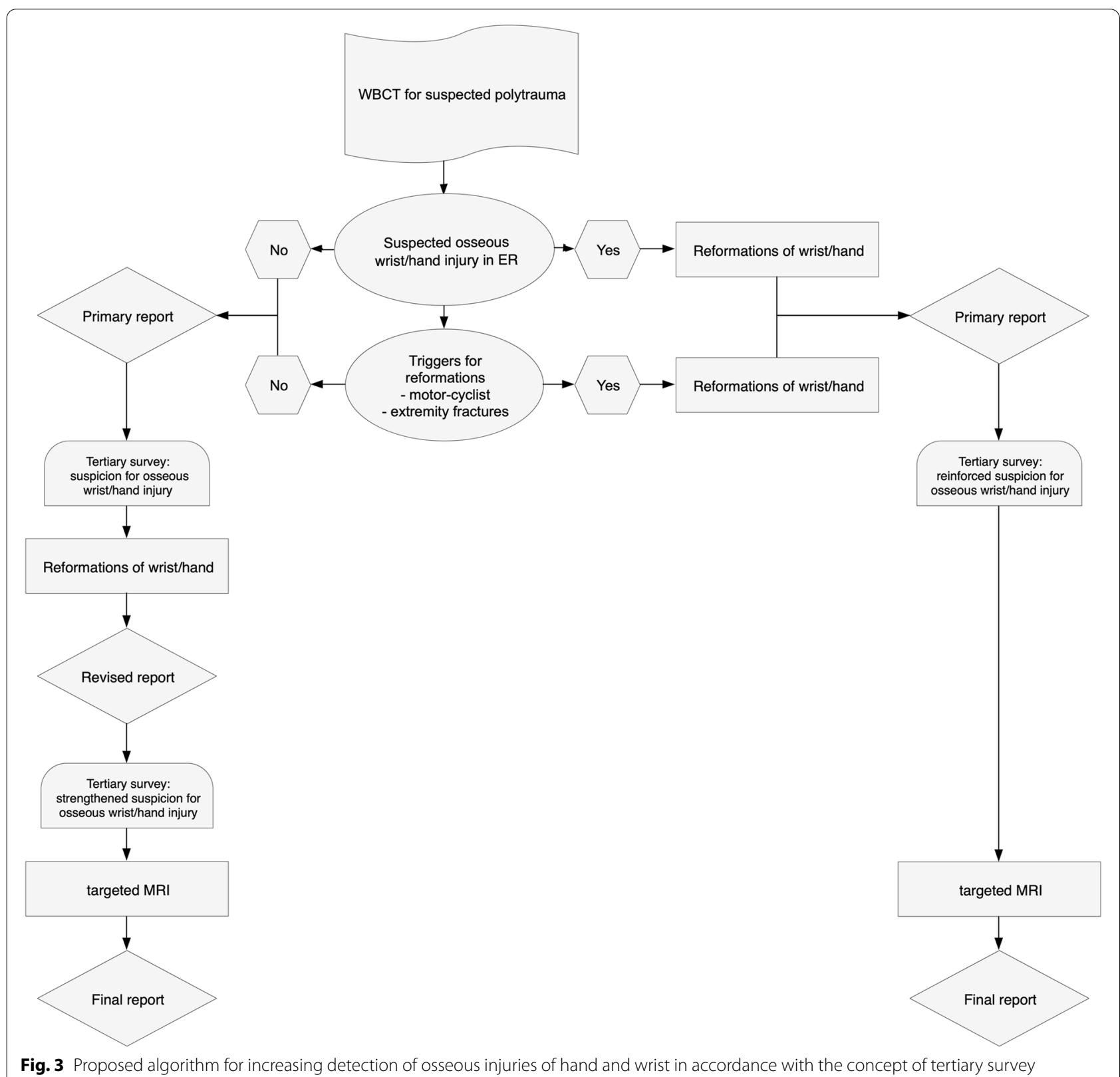

Fig. 3 Proposed algorithm for increasing detection of osseous injuries of hand and wrist in accordance with the concept of tertiary survey 
and are mobilized [33]. Re-evaluation of existing imaging should be part of tertiary surveys and can reduce the number of missed injuries further [34, 35]. Together with primary triggers for profound engagement with a patient's wrist and hand after polytrauma on WBCT, such as the type of accident and injury patterns, the results of secondary or tertiary clinical examinations and raised suspicions could be regarded as a second chance not only to review existing imaging but to prepare the necessary multiplanar reformations and confirm or exclude osseous injuries without further radiation exposure in a timely fashion [36]. In cases of doubt, targeted MRI might be an option to detect even occult fractures after stabilization of polytrauma patients [37, 38] (Fig. 3). Targeted MRI also enables identification of soft-tissue injuries after (sub-) luxations which reposition spontaneously and are therefore impossible to detect on WBCT reformations. Symptomatic patients with inconclusive CT reformations should thus be examined until all imaging methods are exhausted.

Improvements in intelligent technologies might enable automated multiplanar reformation of complex structures such as hand and wrist from WBCT in the future and further increase detection rates and diagnostic performance [39].

\section{Limitations}

Certain limitations of this study must be addressed. First, the retrospective study design is susceptible to selection bias and missing data. By adhering to the STROBE standards, transparency of the inclusion process of consecutive patients was essential as a countermeasure. Secondly, the exploratory study design and lack of sample size calculations results in limited comparisons. On the other hand, significant differences, such as a higher number of motorcyclists among patients with osseous wrist and hand injuries, are likely to be reliable. In addition, despite the single-center design, the large number of cases with a total of 1012 multiplanar reformatted wrists/hands is one of the strengths of the study. Patient records could be accessed in detail and reasons for missing data were reduced. Lastly, interobserver comparison of the reference tests were not part of the study. Nevertheless, all included cases, wrists and hands were reviewed and thus diagnostic accuracy could be measured on a gold standard as demanded by the STARD Guidelines [19].

\section{Conclusion}

Osseous wrist and hand injuries are present in $11.7 \%$ on WBCT after polytrauma. 93.2\% of injuries were missed primarily, resulting in a very low sensitivity of WBCT during primary reporting. Motorcycle accidents might predispose for these injuries, and they often cause additional injuries of the upper and/or lower extremities (Fig. 2).

Clinical re-examination of patients and careful re-evaluation of WBCT with preparation of specific multiplanar reformations are essential in polytrauma cases to detect osseous injuries of wrist and hand reliably.

Targeted MRI should be performed to identify occult fractures and soft-tissue injuries in symptomatic patients with inconclusive $\mathrm{CT}$ results in the post-acute phase after severe injuries.

\section{Abbreviations}

WBCT: Whole-body computed tomographies; CT: Computed tomography; DRKS: German register for clinical trials (Deutsches Register Klinischer Studien); STROBE: Strengthening the Reporting of Observational Studies in Epidemiology; RR: Radiology report; ICU: Intensive care unit; GCS: Glasgow Coma Scale; STARD: Standards for Reporting of Diagnostic Accuracy; TP: True positives; FP: False positives; TN: True negatives; FN: False negatives; PPV: Positive predicted values; NPV: Negative predicted values; Cl: Confidence intervals; SD: Standard deviation; ER: Emergency room; ALARA: As low as reasonably achievable.

\section{Acknowledgements}

None.

\section{Authors' contributions}

LS: data acquisition, data interpretation, manuscript preparation; AH statistical analysis, draft revision; AA: patient follow-up, draft revision. SK: data interpretation, draft revision; AE: study planning, draft revision, SM: image analysis, data revision; LG: image analysis, data interpretation, manuscript preparation. All authors read and approved the final manuscript.

\section{Funding}

No funding was received by any of the authors to conduct this study.

\section{Availability of data and materials}

The datasets generated and analyzed during the current study are not publicly available due to privacy restrictions but are available from the corresponding author in an anonymized form on reasonable request.

\section{Declarations}

\section{Ethics approval and consent to participate}

This study was conducted in accordance with the Declaration of Helsinki 2013. The institutional review board (Medical Association of Berlin, Germany, Eth-45/20) approved the study protocol and waived the necessity for written consent.

\section{Consent for publication}

Not applicable.

\section{Competing interests}

The authors declare that they have no competing interests.

\author{
Author details \\ ${ }^{1}$ Department of Radiology and Neuroradiology, BG Klinikum Unfallkrank- \\ enhaus Berlin, Warener Str. 7, 12683 Berlin, Germany. ${ }^{2}$ Center for Clinical \\ Research, BG Klinikum Unfallkrankenhaus Berlin, Berlin, Germany. ${ }^{3}$ Department \\ of Hand-, Replantation- and Microsurgery, BG Klinikum Unfallkrankenhaus \\ Berlin, Berlin, Germany. ${ }^{4}$ Department of Hand Surgery and Microsurgery, \\ University Medicine Greifswald, Greifswald, Germany. ${ }^{5}$ Institute for Diagnostic \\ Radiology and Neuroradiology, University Medicine Greifswald, Greifswald, \\ Germany.
}


Received: 27 July 2021 Accepted: 27 September 2021

Published online: 11 October 2021

\section{References}

1. Janjua KJ, Sugrue M, Deane SA. Prospective evaluation of early missed injuries and the role of tertiary trauma survey. J Trauma. 1998;44(6):10007. https://doi.org/10.1097/00005373-199806000-00012

2. Eurin M, Haddad N, Zappa M, Lenoir T, Dauzac C, Vilgrain V, et al. Incidence and predictors of missed injuries in trauma patients in the initial hot report of whole-body CT scan. Injury. 2012;43(1):73-7. https://doi. org/10.1016/j.injury.2011.05.019 Epub 2011 Jun 12. PMID: 21663908.

3. Pehle B, Kuehne CA, Block J, Waydhas C, Taeger G, Nast-Kolb D, et al. Die Bedeutung von verzögert diagnostizierten Läsionen bei Polytraumatisierten. Eine Studie an 1187 Schockraumpatienten [The significance of delayed diagnosis of lesions in multiply traumatised patients. A study of 1,187 shock room patients]. Unfallchirurg. 2006;109(11):964-74. https:// doi.org/10.1007/s00113-006-1161-y discussion 975-6. German. PMID: 17058060.

4. Roessle TR, Freitas CD, Moscovici HF, Zamboni C, Hungria JOS, Christian RW, et al. Tertiary assessment of trauma patients in a hospital in the city of São Paulo: a question of necessity. Rev Bras Ortop. 2013;48(4):357-61. https://doi.org/10.1016/j.rboe.2012.08.007 PMID: 31304133; PMCID: PMC6565909.

5. Thomson CB, Greaves I. Missed injury and the tertiary trauma survey. Injury. 2008;39(1):107-14. https://doi.org/10.1016/j.injury.2007.07.030.

6. Kahn J, Grupp U, Maurer M. How does arm positioning of polytraumatized patients in the initial computed tomography (CT) affect image quality and diagnostic accuracy? Eur J Radiol. 2014;83(1):e67-71. https:// doi.org/10.1016/j.ejrad.2013.10.002.

7. Hickethier T, Mammadov K, Baeßler B, Lichtenstein T, Hinkelbein J, Smith $L$, et al. Whole-body computed tomography in trauma patients: optimization of the patient scanning position significantly shortens examination time while maintaining diagnostic image quality. Ther Clin Risk Manag. 2018;14:849-59. https://doi.org/10.2147/TCRM.S162074 PMID: 29765226; PMCID: PMC5944460.

8. Yin ZG, Zhang JB, Kan SL, Wang XG. Diagnostic accuracy of imaging modalities for suspected scaphoid fractures: meta-analysis combined with latent class analysis. J Bone Joint Surg Br. 2012;94(8):1077-85. https://doi.org/10.1302/0301-620X.94B8.28998.

9. Houshian S, Larsen MS, Holm C. Missed injuries in a level I trauma center. J Trauma. 2002;52(4):715-9. https://doi.org/10.1097/00005373-20020 4000-00018.

10. Pfeifer R, Pape HC. Missed injuries in trauma patients: A literature review. Patient Saf Surg. 2008;2:20. Published 2008 Aug 23. https://doi.org/10. 1186/1754-9493-2-20.

11. Ferree S, van der Vliet QMJ, van Heijl M, Houwert RM, Leenen LPH, Hietbrink F. Fractures and dislocations of the hand in polytrauma patients: incidence, injury pattern and functional outcome. Injury. 2017;48(4):9305. https://doi.org/10.1016/j.injury.2017.02.034.

12. Fitschen-Oestern $S$, Lippross $S$, Lefering $R, K$ Klüter T, Behrendt $P$, Weuster $M$, et al. Missed hand and forearm injuries in multiple trauma patients: an analysis from the TraumaRegister DGU ${ }^{\circledR}$. Injury. 2020;51(7):1608-17. https://doi.org/10.1016/j.injury.2020.04.022 Epub 2020 May 8. PMID: 32434714.

13. Münn F, Laun RA, Asmus A, Bülow R, Bakir S, Haralambiev L, et al. Detection of fractures of hand and forearm in whole-body CT for suspected polytrauma in intubated patients. BMC Musculoskelet Disord. 2020;21(1):49. https://doi.org/10.1186/s12891-020-3068-0 PMID: 31969135; PMCID: PMC6977285.

14. Kim S, Goelz L, Münn F, Kim D, Millrose M, Eisenschenk A, et al. Detection of missed fractures of hand and forearm in whole-body $C T$ in a blinded reassessment. BMC Musculoskelet Disord. 2021;22(1):589. https://doi.org/ 10.1186/s12891-021-04425-z PMID: 34174869; PMCID: PMC8236191.

15. Mark G. Das Schicksal des polytraumatisierten Patienten mit einer "Bagatellverletzung" an der hand [the fate of the polytraumatized patient with a "minor injury" of the hand]. Handchir Mikrochir Plast Chir. 1989;21(1):51-4.
16. Ciclamini D, Panero B, Titolo P, Tos P, Battiston B. Particularities of hand and wrist complex injuries in polytrauma management. Injury. 2014;45(2):448-51. https://doi.org/10.1016/j.injury.2013.09.016.

17. Neugebauer E, Krettek C; German Society of Trauma Surgery (DGU). S3-Leitlinie Polytrauma/Schwerverletzten-Behandlung. Auf die Implemetierung kommt es an! [S3 guidelines on treatment of polytrauma/ severe injuries. What matters is the implementation!]. Unfallchirurg. 2012;115(1):6-7. doi: https://doi.org/10.1007/s00113-011-2101-z. PMID: 22274597

18. von Elm E, Altman DG, Egger M, Pocock SJ, Gøtzsche PC, Vandenbroucke JP. STROBE-Initiative. Das Strengthening the Reporting of Observational Studies in Epidemiology (STROBE-) Statement [The Strengthening the Reporting of Observational Studies in Epidemiology (STROBE) statement: guidelines for reporting of observational studies]. Internist (Berl). 2008;49(6):688-93. https://doi.org/10.1007/s00108-008-2138-4 German. PMID: 18511988

19. Bossuyt PM, Reitsma JB, Bruns DE, Gatsonis CA, Glasziou PP, Irwig L, et al. STARD Group. STARD 2015: an updated list of essential items for reporting diagnostic accuracy studies. BMJ. 2015;351:h5527. https://doi.org/10. 1136/bmj.h5527 PMID: 26511519; PMCID: PMC4623764.

20. Lendemans S, Ruchholtz S. German Society of Trauma Surgery (DGU). S3-Leitlinie Polytrauma/Schwerverletzten-Behandlung. Schockraumversorgung [S3 guideline on treatment of polytrauma/severe injuries. Trauma room care]. Unfallchirurg. 2012;115(1):14-21. https://doi.org/10. 1007/s00113-011-2103-x German. PMID: 22274599.

21. Clopper CJ, Pearson ES. The use of confidence or Fiducial limits illustrated in the case of the binomial. Biometrika. 1934;26:404-13. https://doi.org/ 10.1093/biomet/26.4.404.

22. Maclntyre NJ, Dewan N. Epidemiology of distal radius fractures and factors predicting risk and prognosis. J Hand Ther. 2016;29(2):136-45. https://doi.org/10.1016/j.jht.2016.03.003 PMID: 27264899.

23. Ferree S, van der Vliet QMJ, Nawijn F, Bhashyam AR, Houwert RM, Leenen $\mathrm{LPH}$, et al. Epidemiology of distal radius fractures in polytrauma patients and the influence of high traumatic energy transfer. Injury. 2018;49(3):630-5. https://doi.org/10.1016/j.injury.2018.02.003 Epub 2018 Feb 5. PMID: 29429577

24. Montmany S, Navarro S, Rebasa P, Hermoso J, Hidalgo JM, Cánovas G. Estudio prospectivo de la incidencia de las lesiones inadvertidas en el paciente politraumatizado [A prospective study on the incidence of missed injuries in trauma patients]. Cir Esp. 2008;84(1):32-6. https://doi. org/10.1016/s0009-739x(08)70601-8 Spanish. PMID: 18590673.

25. Chen CW, Chu CM, Yu WY, Lou YT, Lin MR. Incidence rate and risk factors of missed injuries in major trauma patients. Accid Anal Prev. 2011;43(3):823-8. https://doi.org/10.1016/j.aap.2010.11.001 Epub 2010 Dec 3. PMID: 21376872

26. Mazahir S, Pardhan A, Rao S. Office hours vs after-hours. Do presentation times affect the rate of missed injuries in trauma patients? Injury. 2015;46(4):610-5. https://doi.org/10.1016/j.injury.2015.01.016 Epub 2015 Jan 16. PMID: 25636534

27. Wei CJ, Tsai WC, Tiu CM, Wu HT, Chiou HJ, Chang CY. Systematic analysis of missed extremity fractures in emergency radiology. Acta Radiol. 2006;47(7):710-7. https://doi.org/10.1080/02841850600806340 PMID: 16950710.

28. Tyson S, Hatem SF. Easily missed fractures of the upper extremity. Radiol Clin N Am. 2015;53(4):717-36. https://doi.org/10.1016/j.rcl.2015.02.013 PMID: 26046507.

29. Pinto A, Berritto D, Russo A, Riccitiello F, Caruso M, Belfiore MP, et al. Traumatic fractures in adults: missed diagnosis on plain radiographs in the Emergency Department. Acta Biomed. 2018;89(1-S):111-23. https://doi. org/10.23750/abm.v89i1-S.7015 PMID: 29350641; PMCID: PMC6179080.

30. Andresz S, Gilchrist J, Gimenez IC, Vermeersch F. Synthesis of the European ALARA network 18th workshop. J Radiol Prot. 2020. https://doi.org/ 10.1088/1361-6498/ab9508 Epub ahead of print. PMID: 32434162.

31. Nekolla EA, Schegerer AA, Griebel J, Brix G. Häufigkeit und Dosis diagnostischer und interventioneller Röntgenanwendungen : Trends zwischen 2007 und 2014 [Frequency and doses of diagnostic and interventional X-ray applications : Trends between 2007 and 2014]. Radiologe. 2017;57(7):555-62. https://doi.org/10.1007/s00117-017-0242-y German. PMID: 28361179

32. Mallee WH, Doornberg JN, Ring D, Maas M, Muhl M, van Dijk CN, et al. Computed tomography for suspected scaphoid fractures: comparison 
of reformations in the plane of the wrist versus the long axis of the scaphoid. Hand (N Y). 2014;9(1):117-21. https://doi.org/10.1007/s11552013-9556-z PMID: 24570648; PMCID: PMC3928374.

33. Keijzers GB, Giannakopoulos GF, Del Mar C, Bakker FC, Geeraedts LM Jr. The effect of tertiary surveys on missed injuries in trauma: a systematic review. Scand J Trauma Resusc Emerg Med. 2012;29(20):77. https://doi. org/10.1186/1757-7241-20-77 PMID: 23190504; PMCID: PMC3546883.

34. Howard J, Sundararajan R, Thomas SG, Walsh M, Sundararajan M. Reducing missed injuries at a level II trauma center. J Trauma Nurs. 2006;13(3):89-95. https://doi.org/10.1097/00043860-200607000-00003 PMID: 17052086.

35. Vles WJ, Veen EJ, Roukema JA, Meeuwis JD, Leenen LP. Consequences of delayed diagnoses in trauma patients: a prospective study. J Am Coll Surg. 2003;197(4):596-602. https://doi.org/10.1016/S1072-7515(03) 00601-X PMID: 14522329.

36. Schädel-Höpfner $M$, Siebert H. Operative Versorgungsstrategien für Handverletzungen beim Polytrauma. Eine systematische Literaturübersicht [operative strategies for hand injuries in multiple trauma. A systematic review of the literature]. Unfallchirurg. 2005;108(10):850-7. https:// doi.org/10.1007/s00113-005-0996-y.
37. Clementson M, Thomsen N, Björkman A. Diagnostik och behandling av akuta skafoideumfrakturer [Scaphoid fractures - Guidelines for diagnosis and treatment]. Lakartidningen. 2019;18:116 FL9M. Swedish. PMID: 31211404.

38. Jørgsholm P, Thomsen NO, Besjakov J, Abrahamsson SO, Björkman A. The benefit of magnetic resonance imaging for patients with posttraumatic radial wrist tenderness. J Hand Surg Am. 2013;38(1):29-33. https://doi. org/10.1016/j.jhsa.2012.09.034 Epub 2012 Nov 30. PMID: 23200950.

39. Scholtz JE, Wichmann JL, Kaup M, Fischer S, Kerl JM, Lehnert T, et al. First performance evaluation of software for automatic segmentation, labeling and reformation of anatomical aligned axial images of the thoracolumbar spine at CT. Eur J Radiol. 2015;84(3):437-42. https://doi.org/10. 1016/j.ejrad.2014.11.043 Epub 2014 Dec 13. PMID: 25554009.

\section{Publisher's Note}

Springer Nature remains neutral with regard to jurisdictional claims in published maps and institutional affiliations.
Ready to submit your research? Choose BMC and benefit from:

- fast, convenient online submission

- thorough peer review by experienced researchers in your field

- rapid publication on acceptance

- support for research data, including large and complex data types

- gold Open Access which fosters wider collaboration and increased citations

- maximum visibility for your research: over 100M website views per year

At BMC, research is always in progress.

Learn more biomedcentral.com/submissions 